\title{
Comparison of Ultrasonogaphy Vs Fluoroscopy Guided Coeliac Plexus Block for Relief of Pain in Chronic Pancreatitis-An Observational Study
}

\author{
Dr. Sourav Mallik ${ }^{1}$, Dr. Dipasri Bhattacharya ${ }^{2}$, Dr. Sankar Roy ${ }^{3}$ \\ ${ }^{1}$ Postgraduate trainee, Dept of Anaesthesiology, RGKar Medial College, Kolkata, West Bengal. \\ ${ }^{2}$ Professor \& HOD, Dept of Anaesthesiology, RGKar Medial College, Kolkata, West Bengal. \\ ${ }^{3} \mathrm{MD}$, Resident Medical Officer cum Clinical Tutor. \\ dipasribhattacharya123@gmail.com
}

*Corresponding Author: Professor \& HOD, Dept of Anaesthesiology, RGKar Medial College, Kolkata, West Bengal.

Abstract

Inroduction: This study was done to compare between Ultrasonography Vs. Fluoroscopy Guided Coeliac plexus block for relief of pain in chronic pancreatitis. The patients were undergoingtreatment at medicine/ gastroenterology/surgery departments of R.G.Kar Medical College(Kolkata) for more than 6 months, not responding to conservative treatment and were referred to pain OPD for subsequent pain management.

Materials and Methods: A group of 32 patients, aged 18-60 years, categorised as ASA III (suffering from chronic pancreatitis and not responding to conservative treatment) were divided into Group $U$ and Group F, undergoing Ultrasonography and Fluoroscopic guided coeliac plexus blocks respectively. Each group consists of 16 patients. Thorough clinical and biochemical tests were done before the procedures. The time of needle placement, reduction of visual analogue scale(VAS) scores, haemodynamic stability, side-effects, patient satisfaction and need for rescue analgesics were compared between the two groups.

\section{Results}

- $\quad$ The time of needle placement was faster in ultrasonography guided procedure ( $p$ Value 0.000).

- In the long term ultrasonography (USG) guided procedure yields greater reduction in VAS score ( $p$ Value 0.006 in 12 weeks).

- The fall in Blood Pressure(BP) in 15 th minute was more in ultrasound guided technique ( $p$ value 0.000), whereas the fall in blood pressure in $30^{\text {th }}$ minute was more in Fluoroscopy guided technique ( $p$ value 0.000 ).

- Side-effects ( $p$ value 0.500), need for rescue analgesics( $p$ value 0.758) were comparable in both groups.

- Patient satisfaction were similar with Ultrasonography than Fluoroscopy techniques ( $p$ value 0.887).

Conclusion: Transabdominal Ultrasonography guided coeliac plexus block (transhepaticapproach) can be a safer, faster, reliable, more patient friendly alternative to Fluoroscopy guided coeliac plexus block (transaortic approach) with better results.

Keywords: Coeliac Plexus Block, Ultrasonography, Fluoroscopy, ASA, VAS Score.

\section{INTRODUCTION}

Coeliac plexus is the largest plexus of sympathetic nervous system that innervates the upper abdominal organs (like pancreas, liver, spleen, stomach, small bowel, ascending colon, proximal part of transverse colon, abdominal aorta, mesentery, adrenals \& kidney) derived from embryonic foregut. It lies embedded in loose areolar tissue in retroperitoneal space posterior to stomach and pancreas, close to the coeliac axis, overlapping the aorta at the level of upper border of first lumbar vertebra (L1). It is composed of pre- and 
Comparison of Ultrasonogaphy Vs Fluoroscopy Guided Coeliac Plexus Block for Relief of Pain in Chronic Pancreatitis - An Observational Study

post-ganglionic sympathetic, parasympathetic and visceral sensory afferent fibres. The efferent fibres innervate the blood vessels and upper abdominal viscera.[1]

The injection of local anaesthetics $(25 \mathrm{ml}$ of $1 \%$ preservative free Lignocaine) and Steroid (depomethyl-prednisolone $80 \mathrm{mg}$ ) in the coeliac plexus disruptsefferent/afferentneuronalsignaltransmission in the spinal cord and reduces inflammation respectively. Thus it interferes with the perception of pain, improving patient morbidity.[1]

It is commonly used in pain related to chronic pancreatitis. Coeliac Plexus Block(CPB) is conventionally performed by percutaneous technique with fluoroscopic guidance. Ultrasound is now evolving as an alternative procedure, as it is easier, faster, reliable, being a bedside procedure and avoiding radiation hazards.[3]

Coeliac Plexus Block (CPB) with local anaesthetic was introduced as early as 1914 primary for surgical anaesthesia. However with the advent of subarachnoid block it was became quite unfavourable among anaesthesiologists.[1]

Later it again became popular due to a crossover of its utility in pain management. Currently it is quite popular for relief of pain in chronic pancreatitis \& upper abdominal visceral pain (malignancies). It is reported to reduce the daily dose of narcotics and analgesics required by such patients. CPB is commonly administered by percutaneous technique with Fluoroscopic Guidance or with transabdominal Ultrasound guided.[4]

As there are very few studies comparing results of trans abdominal Ultrasonography vs. Fluoroscopy guided coeliac plexus block for pain reduction in chronic pancreatitis patients, so this study was undertaken by us.

In this study the following was compared between the two procedures

a) The degree of pain relief among patients measured by Visual Analogue Scale (VAS).

b) The reduction in dose/frequency of Opioids/ Other analgesics.

c) Adverse Effects.

d) Haemodynamic Effects.

e) Patient Satisfaction ( reduction in VAS scores/ pain perception and improvement of pain free days).

f) Time of needle placement.

\section{MATERIALS AND METHOdS}

The study was conducted on patients diagnosed as chronic pancreatitis by the General Medicine/ Surgery/ Gastroenterology department of R.G.Kar $\mathrm{MC} \& \mathrm{H}$, not responding to conservative management and referred to our pain clinic for pain management. They were aged between 18-60 years, belonging to ASA III category. Approval from the institutional ethics committee and written informed consent from the patients was taken prior to the study.

This study was a prospective observational study. So far as we could search, no other study similar to this was found. So all patients referred to the pain clinic by the respective departments were taken into sample size. We have assumed the power of our study to be $80 \%$ with a probability level of 0.05 (i.e confidence interval of 95\%). The study was conducted from December 2017 to November 2018 (1 year) in the pain opd and pain intervention OT of R.G.Kar Medical College, Kolkata.

The patients were divided into two (2) groups- U \& F. Group U underwent Ultrasonography guided Coeliac Plexus block and Group F underwent Fluoroscopy Guided Coeliac Plexus Block respectively. There were 16 patients in each group. Their allocation was done randomly. The procedure was thoroughly explained to the patients and written consent was taken from them.Routine biochemical tests, serology, ECG, CxR (PA,) prior USG/CT Scan whole abdomen with documented opinion from the radiologist,proper history, clinical examination were done prior to the procedure.

All patients were advised to have their usual meals the day before the procedure, fasting 8hours for solid food and 2 hours for clear fluids. They were prescribed tablet Pantoprazole $40 \mathrm{mg}$ at $6 \mathrm{am}$ on day of procedure and Bisacodyl (Dulcolax) rectal suppositories the night before the procedure. They also took their regular medicines (except analgesics)at 6am on day of procedure. I.V line was secured with a $18 \mathrm{G}$ cannula and Ringers Lactate was infused at $100 \mathrm{ml} / \mathrm{hr}$. Pre-loading 
Comparison of Ultrasonogaphy Vs Fluoroscopy Guided Coeliac Plexus Block for Relief of Pain in Chronic Pancreatitis - An Observational Study

with $500 \mathrm{ml}$ of crystalloid was done. Monitoring of blood pressure, pulse, SpO2, respiratory rate and ECG was done. All resuscitation equipments, monitors and Anaesthesia Machine were kept ready. Nasal 02 was administered at $4 \mathrm{~L} / \mathrm{min}$. Pre-procedural VAS score was noted.

Time needed from completion of dressing-draping to proper needle placement was noted and a test dose of $10 \mathrm{ml} 1 \%$ preservative free lignocaine was injected after a negative aspiration for blood. If patient reports a reduction in pain, it indicates close proximity of needle to celiac plexus. Then $80 \mathrm{mg}$ of depo methyl prednisolone with $10 \mathrm{ml}$ of $1 \%$ preservative free lignocaine was injected with intermediate aspiration and flushed with $2 \mathrm{ml}$ of normal saline(NS).

Pain relief was assessed by help of Visual Analogue Scale (VAS) score. VAS scores were recorded just before the procedure, just after the procedure, after 2 weeks, 4 weeks , 8 weeks and 12 weeks.

Complications and adverse effects were noted and treated accordingly.

Patient satisfaction (good/fair/bad) were noted and also reduction of rescue analgesics. Patients were advised dietary restrictions, quit addictions, take pancreatin enzyme supplementations and painmodifying drugs.

\section{INCLUSION CRITERIA}

1. Diagnosed as chronic pancreatitis not responding to conservative management and referred to pain clinic for pain management.

2. Requiring opiods/NSAIDS for more than 6 months.

3. Age 18-60 years.

\section{EXCLUSION CRITERIA}

1. Pancreatic Carcinoma.

2. Necrotising pancreatitis.

3. Gall stone pancreatitis

4. Patients with coagulopathy, anti-cancer therapy.

5. Local/ intra-abdominal sepsis.

6. Bowel Obstruction.

7. Uncontrolled Diabetes.

8. Patients on disulfiram therapy for alcohol abuse.

9. Pregnancy and lactation.

10. Uncooperative patients or patient's refusal.

11. Cardiac or neurological diseases.

12. On anti-pyschotics.

13. ECG abnormalities.

14. Pancreatic Surgeries already performed, like lateral pancreatico-jejunostomy (LPJ).

\section{PROCEDURES}

\section{Usg Guilded Coeliac Plexus Block}

The patient lies in supine position with hands by the side. The anaesthesia machine was kept ready and blood pressure cuff, pulse oximeter, ECG leads were attached to the patient. An intravenous line was secured with a 18G cannula and Ringers Lactate was infused. All other resuscitation tools were kept ready. Pre-operative VAS was noted.

The abdomen was exposed and preliminary USG was done to have an idea about the expected site of injection. The settings in the USG machine were accordingly adjusted to have a clear image. Then after proper hand washing, wearing sterile gloves, the abdomen was painted first with spirit then betadine and then again with spirit for proper asepsis. A cut sheet was put over abdomen so as to well demarcate the area of interest. The convex transducer was draped with sterile glove. Sterile jelly was used and the transducer was first put over the xiphisternum. The cardiac chambers were visualized with the valves opening and closing according to the phase of the cardiac cycle.

The the transducer was traced downwards until the "seagull sign" was seen. The probe was then over the region of the epigastrium. The vertebral body was seen posteriorly, the anterior border of the vertebra was white with an acoustic shadow behind. The inferior vena cava (IVC) and the pulsatile abdominal aorta was seen anterior to the vertebral body. The coeliac trunk was seen as a pulsatile "hood" over the abdominal aorta. The coeliac trunk (body of the sea gull) bifurcating into the splenic (left side)and common hepatic arteries(right side) - forming the wings of "the sea gull". The coeliac plexus is seen as a glistening mass in between the coeliac trunk and abdominal aorta.

Archives of Anesthesiology V2 . I1 . 2019 
Comparison of Ultrasonogaphy Vs Fluoroscopy Guided Coeliac Plexus Block for Relief of Pain in Chronic Pancreatitis - An Observational Study

Skin was infiltrated with $1 \%$ preservative free lignocaine. A $15 \mathrm{~cm} 22 \mathrm{G}$ spinal needle was introduced from the right side of the patient (in-plane technique) under USG guidance. The needle passed through left lobe of liver, hence called trans-hepatic approach. Once the needle was in the coeliac plexus (between aorta and the coeliac trunk) a negative aspirate for blood was done, followed by injection of $10 \mathrm{ml}$ of $1 \%$ preservative free lignocaine. If patient reports a reduction of his/ her pain then it denotes a positive diagnostic test, the needle being in close proximity to the coeliac plexus.
Then 80mgdepo-methyl prednisolone and $10 \mathrm{ml}$ of $1 \%$ preservative free lignocaine was injected with intermittent negative aspiration for blood and flushed with $2 \mathrm{ml}$ of normal saline.

The patient was closely monitored with respect to pulse, B.P, $\mathrm{SpO}_{2}$ and other adverse effects. Hypotension was the most common problem encountered. The patient was observed for 30mins on table before shifting to post-procedural recovery room, where he/ she was observed for another 2 hours. Post procedural VAS scores were noted.

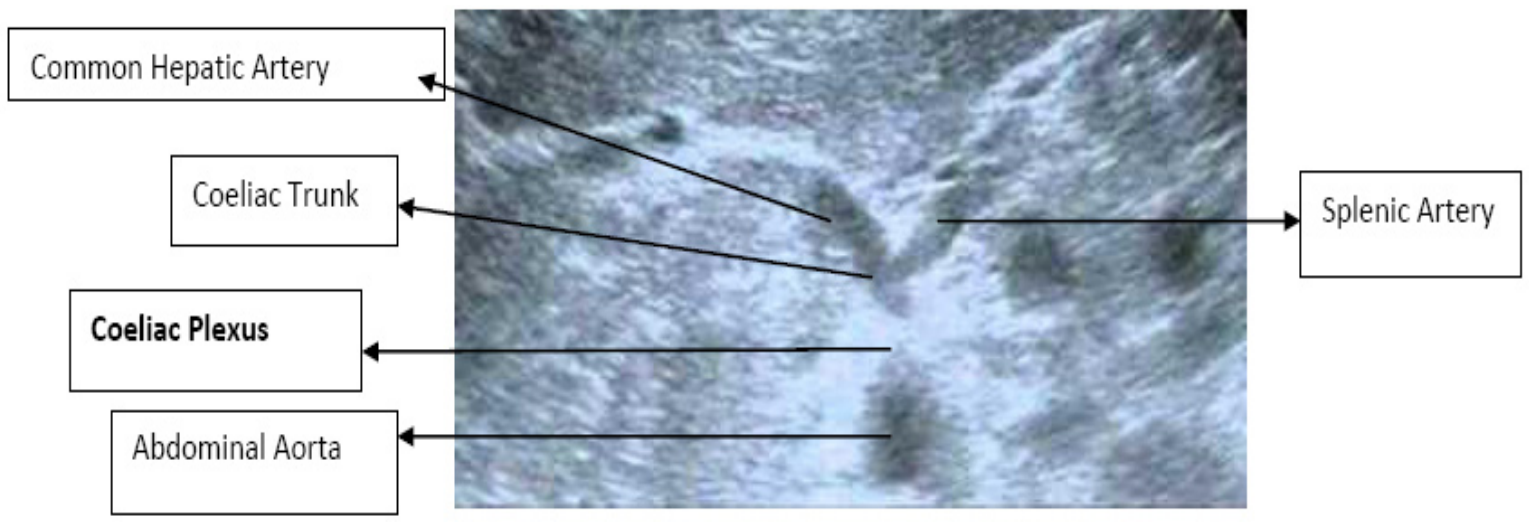

The "Sea Gull Sign" and "Hooded" appearance of the coeliac trunk above the abdominal aorta

The common hepatic artery and splenic artery form the wings of the sea-gull, while the coeliac trunk forms the body.

\section{Fluoroscopy Guided Coeliac Plexus BLOCK}

The technique followed was the posterior transaortic approach. The patient lies prone in bed with a pillow under the abdomen. Pre-procedural VAS score was noted. The anaesthesia machine was kept ready and blood pressure cuff, pulse oximeter, ECG leads were attached to the patient. An intravenous line was secured with a $18 \mathrm{G}$ cannula and Ringers Lactate was infused. All other resuscitation tools were kept ready.

The back was draped with spirit, betadine, spirit (in this succeeding order) and covered with cut sheet exposing only the area of interest. Radiographic (C-arm) guidance was used to visualize the vertebrae. The tip of the L1 spine was located both by palpation and using C-arm guidance. An imaginary isolateral triangle is drawn. The base is on either side (about $7.5 \mathrm{~cm}$ on each side) of the spinous process of the L1 vertebrae, the terminal points are the points of intersection of the $12^{\text {th }}$ ribs with the paraspinal muscles. From there the two arms of the isosceles triangle are traced cranially to meet at the apex on the vertebral body. The coeliac plexus is commonly approached from the left side using a $22 \mathrm{G} 15 \mathrm{~cm}$ long needle.

Local infiltration was done with $1 \%$ preservative free lignocaine. A shot of the C-arm was taken in anteroposterior (AP) view to view the T12-L1 vertebral junction. The $15 \mathrm{~cm}$ long needle was advanced till it reached the junction of T12-L1. The C-arm was then positioned to have a lateral view. The needle was then advanced 1-2 $\mathrm{cm}$ anterior to the upper border of the L1 vertebrae till the dense wall of abdominal aorta was pierced and there was appearance of blood on withdrawal of stillet. $2 \mathrm{ml}$ of radio-opaque dye was injected to confirm cranio-caudal spread of dye. Then a test dose of $10 \mathrm{ml} 1 \%$ preservative free lignocaine was injected and patient was asked if it affords a reduction in his/her pain. If the diagnostic test was positive then $80 \mathrm{mg}$ of depo-methyl prednisolone and $10 \mathrm{ml}$ of $1 \%$ preservative lignocaine was injected and flushed with $2 \mathrm{ml}$ of normal saline.

The patient was closely monitored with respect to 
Comparison of Ultrasonogaphy Vs Fluoroscopy Guided Coeliac Plexus Block for Relief of Pain in Chronic Pancreatitis - An Observational Study

pulse, B.P, $\mathrm{SpO}_{2}$ and other adverse effects. Hypotension was the most common problem encountered. The patient was observed for $30 \mathrm{mins}$ on table before shifting to post-procedure recovery room, where he/ she was observed for another 2 hours. Post procedural VAS scores were noted.

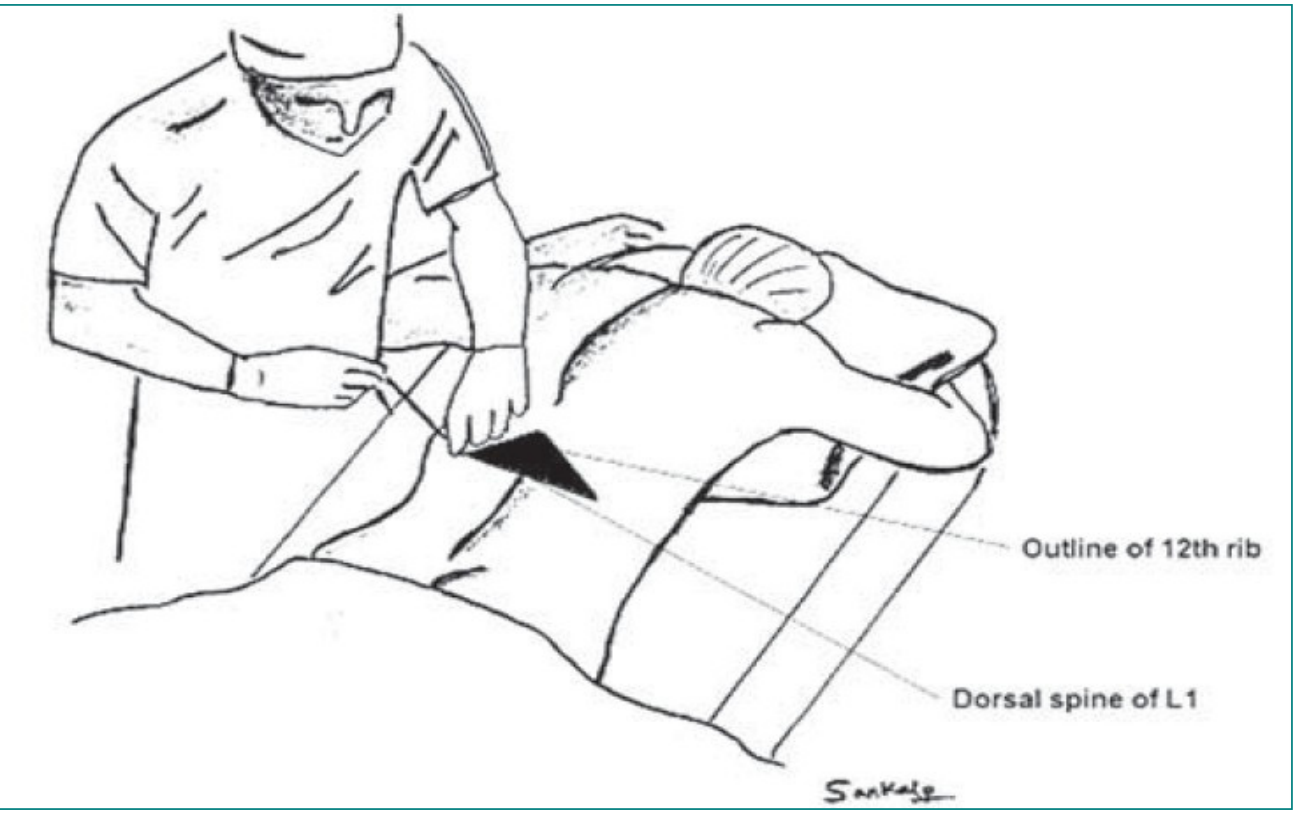

DEMOGRAPHIC DATA

\begin{tabular}{|l|l|l|l|l|l|}
\hline & Group U(n=16) & Group F(n=16) & Statistical Test & $\begin{array}{l}\text { P } \\
\text { Value }\end{array}$ & \multicolumn{1}{|c|}{$\begin{array}{c}\text { Statistical } \\
\text { Significance }\end{array}$} \\
\hline $\begin{array}{l}\text { AGE (in } \\
\text { yrs) }\end{array}$ & $40.81 \pm 10.641$ & $36.38 \pm 9.091$ & $\begin{array}{l}\text { Independent } \\
\text { t Test }\end{array}$ & 0.214 & Not Significant \\
\hline $\begin{array}{l}\text { SEX(Male / } \\
\text { Female) }\end{array}$ & $\begin{array}{l}12(75 \%) \\
4(25 \%)\end{array}$ & $\begin{array}{l}10(62.5 \%) \\
6(37.5 \%)\end{array}$ & Chi Square test & 0.704 & Not Significant \\
\hline $\begin{array}{l}\text { HEIGHT(in } \\
\text { metres) }\end{array}$ & $1.514 \pm 0.047$ & $1.548 \pm 0.056$ & $\begin{array}{l}\text { Independent } \\
\text { t Test }\end{array}$ & 0.077 & Not Significant \\
\hline $\begin{array}{l}\text { WEIGHT(in } \\
\text { Kg) }\end{array}$ & $56.438 \pm 6.673$ & $61.438 \pm 8.563$ & $\begin{array}{l}\text { Independent } \\
\text { t Test }\end{array}$ & 0.075 & Not Significant \\
\hline BMI & $24.633 \pm 2.929$ & $25.600 \pm 3.152$ & $\begin{array}{l}\text { Independent } \\
\text { t Test }\end{array}$ & 0.376 & Not Significant \\
\hline
\end{tabular}

The demographic data was comparable with no significant difference between the two groups in terms of age, gender, height, weight, BMI, Smoking and The data is pictorially depicted below by means of bar diagrams.

Fastness of NeEdle Placement

\begin{tabular}{|c|c|c|c|c|c|}
\hline & $\begin{array}{c}\text { GROUP U } \\
(\mathbf{n = 1 6 )}\end{array}$ & $\begin{array}{c}\text { GROUP } \mathbf{~} \\
(\mathbf{n = 1 6 )}\end{array}$ & TEST APPLIED & p VALUE & RESULT \\
\hline $\begin{array}{c}\text { TIME OF NEEDLE } \\
\text { PLACEMENT } \\
\text { (in mins) }\end{array}$ & $13.047 \pm 1.033$ & $29.063 \pm 5.431$ & $\begin{array}{c}\text { Independent } \\
\text { t Test }\end{array}$ & 0.000 & Significant \\
\hline
\end{tabular}

Archives of Anesthesiology V2 . I1 . 2019 
Comparison of Ultrasonogaphy Vs Fluoroscopy Guided Coeliac Plexus Block for Relief of Pain in Chronic Pancreatitis - An Observational Study

It is seen that the mean needle placement time in USG Guided Proc edure is much faster than Fluroscopy guided procedure.

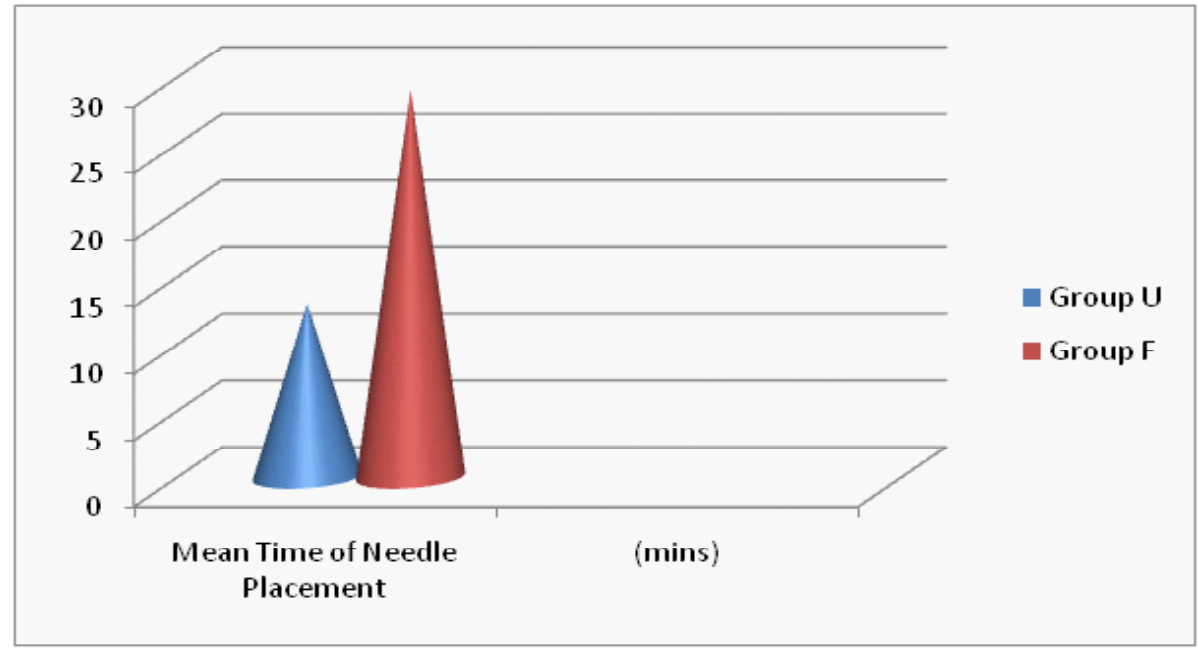

\section{Reduction of Post Operative Mean Vas Score}

\begin{tabular}{|l|c|c|c|c|c|}
\hline \multicolumn{1}{|c|}{$\begin{array}{c}\text { MEAN VAS } \\
\text { REDUCTION AT }\end{array}$} & $\begin{array}{c}\text { GROUP U } \\
\mathbf{( N = 1 6 )}\end{array}$ & $\begin{array}{c}\text { Group F } \\
\mathbf{( N = 1 6 )}\end{array}$ & TEST APPLIED & P. VALUE & RESULT \\
\hline Pre-procedure & $8.063 \pm 0.854$ & $8.063 \pm 0.998$ & $\begin{array}{c}\text { Indpendant } \\
\text { t Test }\end{array}$ & 1.000 & Not Significant \\
\hline $\mathbf{4}$ WEEKS & $0.19 \pm 0.750$ & $0.56 \pm 1.36$ & $\begin{array}{c}\text { Independent } \\
\text { t Test }\end{array}$ & 0.343 & Not Significant \\
\hline $\mathbf{8}$ WEEKS & $1.06 \pm 1.84$ & $2.44 \pm 1.78$ & $\begin{array}{c}\text { Independent } \\
\text { t Test }\end{array}$ & 0.040 & Significant \\
\hline $\mathbf{1 2}$ WEEKS & $1.63 \pm 1.92$ & $3.63 \pm 1.89$ & $\begin{array}{c}\text { Independent } \\
\text { t Test }\end{array}$ & 0.006 & Significant \\
\hline
\end{tabular}

Mean VAS Scores just after the procedure and at the end of 2 weeks were reported as zero (no pain) in both groups. So they have not been tabulated above.

There is no significant difference in VAS score between the two Groups in the $4^{\text {th }}$ week post-procedure.

However, there is a significant difference in VAS scores between the two groups in the $8^{\text {th }}$ and $12^{\text {th }}$ week postprocedure.

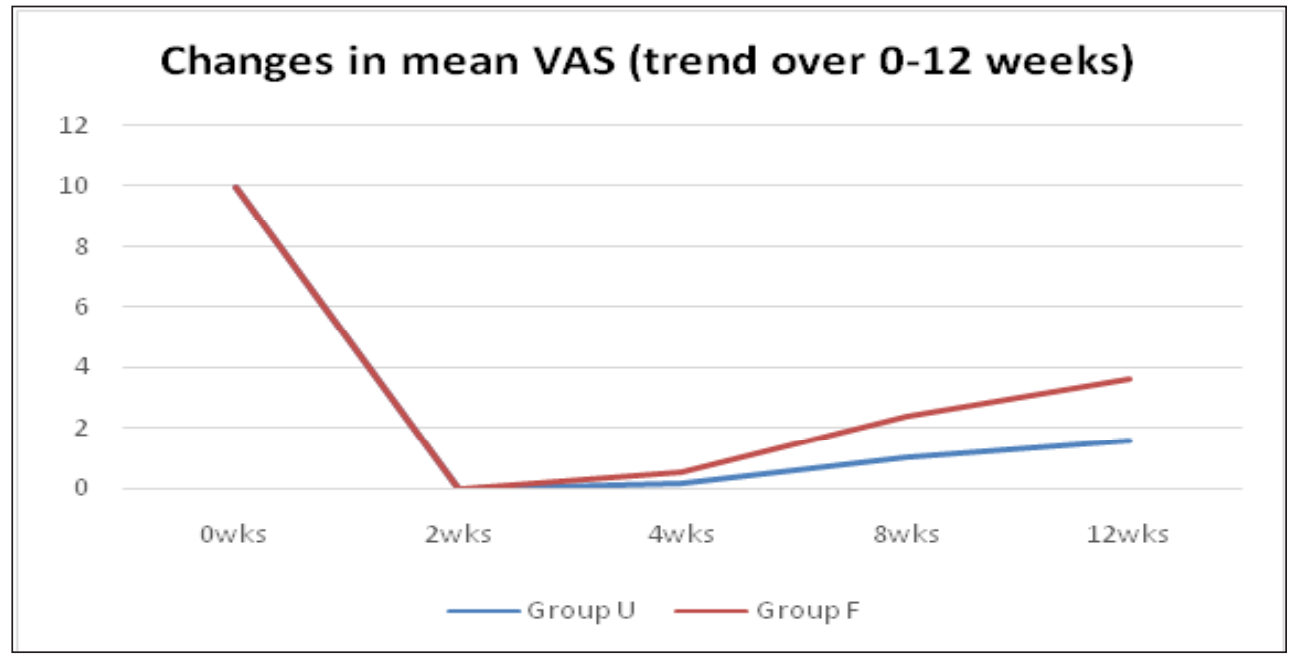


Comparison of Ultrasonogaphy Vs Fluoroscopy Guided Coeliac Plexus Block for Relief of Pain in Chronic Pancreatitis - An Observational Study

Changes of Mean Systolic and Diastolic BP

\begin{tabular}{|l|l|l|l|l|l|}
\hline & GROUP U (n=16) & GROUP F(n=16) & TEST APPLIED & P VALUE & RESULT \\
\hline SBP0 (mm of Hg) & $121.88 \pm 11.13$ & $122.88 \pm 7.83$ & $\begin{array}{l}\text { Independent } \\
\text { t Test }\end{array}$ & 0.771 & Not Significant \\
\hline SBP15 (mm of Hg) & $104.63 \pm 11.42$ & $132 \pm 6.367$ & $\begin{array}{l}\text { Independent } \\
\text { t Test }\end{array}$ & 0.000 & Significant \\
\hline SBP30 (mm of Hg) & $114.25 \pm 7.585$ & $104.63 \pm 5.691$ & $\begin{array}{l}\text { Independent } \\
\text { t Test }\end{array}$ & 0.000 & Significant \\
\hline SBP45 (mm of Hg) & $117.50 \pm 5.08$ & $119.38 \pm 5.55$ & $\begin{array}{l}\text { Independent } \\
\text { t Test }\end{array}$ & 0.327 & Not Significant \\
\hline DBP0 (mm of Hg) & $84.50 \pm 7.78$ & $88.25 \pm 5.69$ & $\begin{array}{l}\text { Independent } \\
\text { t Test }\end{array}$ & 0.130 & Not Significant \\
\hline DBP15 (mm of Hg) & $72.88 \pm 7.991$ & $84.63 \pm 5.315$ & $\begin{array}{l}\text { Independent } \\
\text { t Test }\end{array}$ & 0.000 & Significant \\
\hline DBP30 (mm of Hg) & $79.50 \pm 5.633$ & $79.31 \pm 5.095$ & $\begin{array}{l}\text { Independent } \\
\text { t Test }\end{array}$ & 0.922 & Not Significant \\
\hline DBP45 (mm of Hg) & $81.25 \pm 4.31$ & $85.19 \pm 4.88$ & $\begin{array}{l}\text { Independent } \\
\text { t Test }\end{array}$ & 0.022 & Significant \\
\hline
\end{tabular}

SBP0 - Mean Systolic Blood Pressure just after completion of dressing and draping.

SBP15-MeanSystolic Blood Pressure after 15mins of starting the procedure.

SBP30-Mean Systolic Blood Pressure after 30mins of starting the procedure.

SBP45-Mean Systolic Blood Pressure after 45mins of starting the procedure.

DBP0-Mean Diastolic Blood Pressure at the starting of the procedure.

DBP15-Mean Diastolic Blood Pressure after 15mins of starting the procedure.
DBP30-Mean Diastolic Blood Pressure after 30mins of starting the procedure.

DBP45-Mean Diastolic Blood Pressure after 45mins of starting the procedure.

There is significant difference in mean systolic BP at 15 minutes and 30 minutes in both the groups respectively.

There is also significant difference in mean diastolic $\mathrm{BP}$ at 15 minutes and 45 minutes in both the groups respectively.

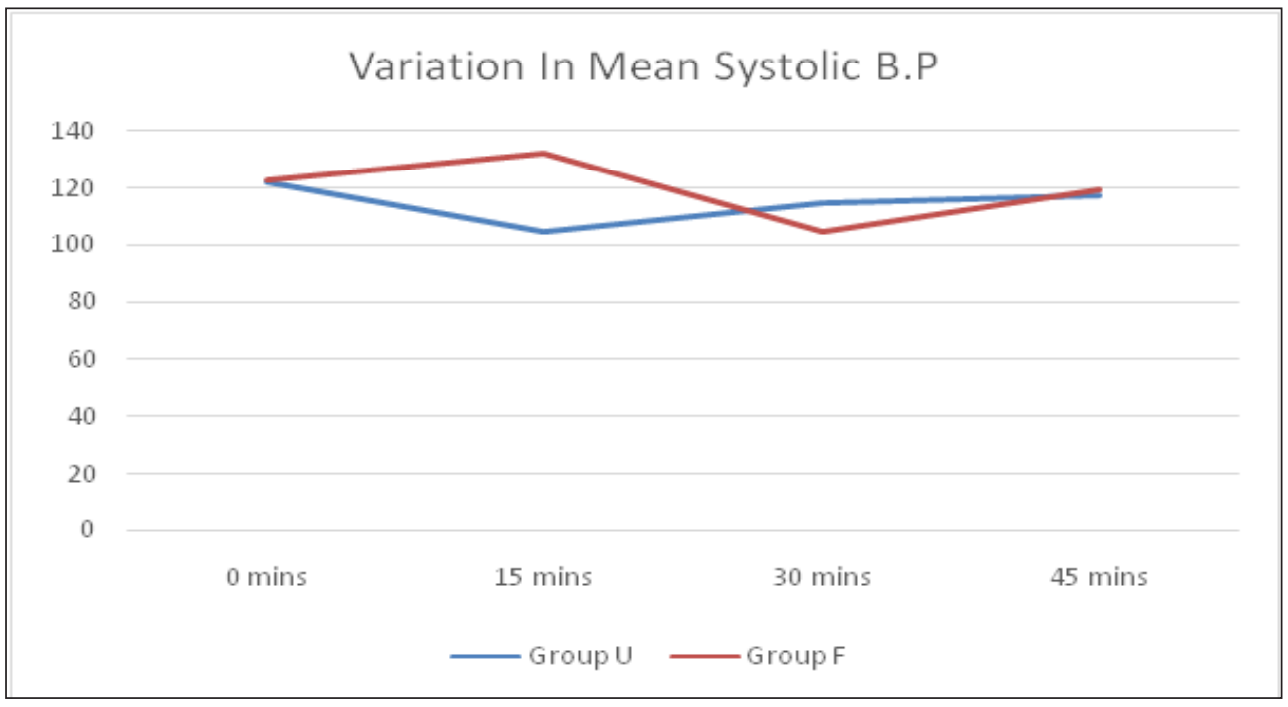

Archives of Anesthesiology V2 . I1 . 2019 
Comparison of Ultrasonogaphy Vs Fluoroscopy Guided Coeliac Plexus Block for Relief of Pain in Chronic Pancreatitis - An Observational Study

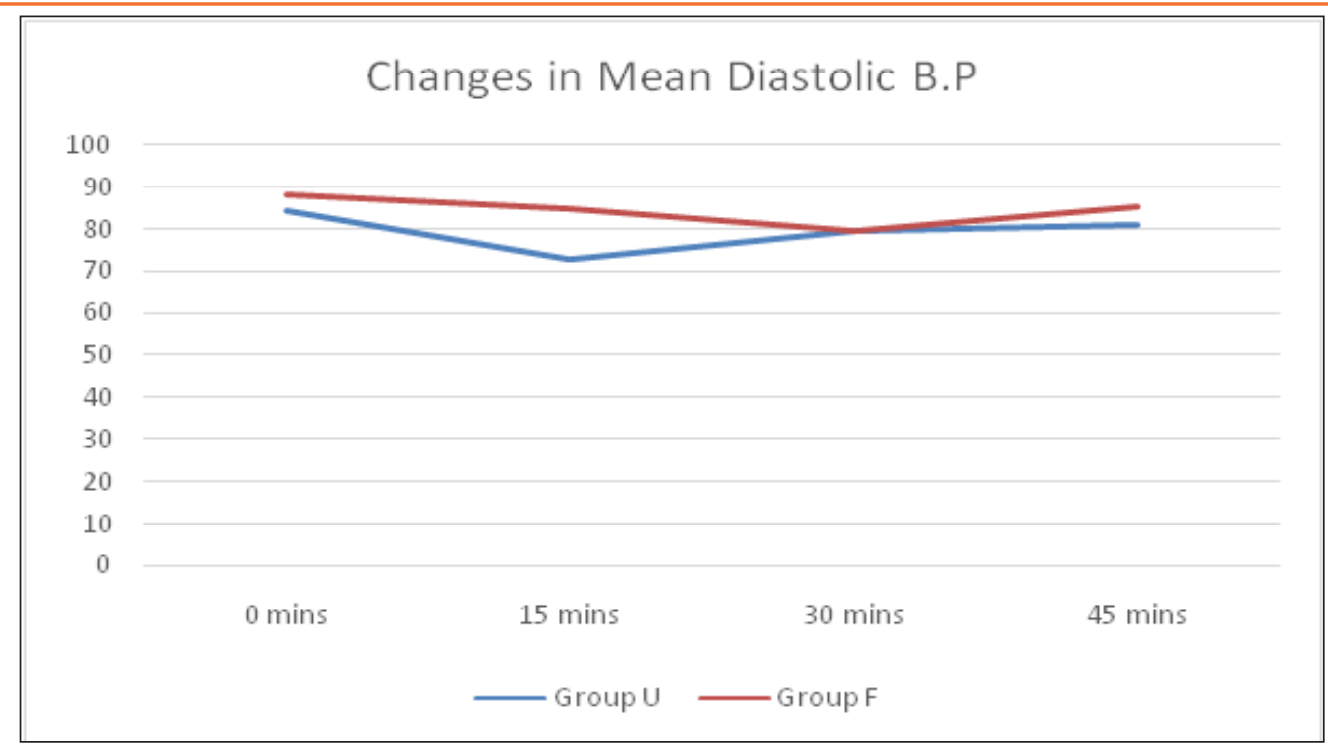

MiscellaneOUS

\begin{tabular}{|c|c|c|c|c|c|}
\hline & GROUP U(n=16) & GROUP F (n=16) & TEST APPLIED & P VALUE & RESULT \\
\hline DIARRHOEA & $3(18.8 \%)$ & $2(12.5 \%)$ & Chi Square & 0.500 & $\begin{array}{c}\text { Not } \\
\text { Significant }\end{array}$ \\
YES/NO & $13(81.3 \%)$ & $14(87.5 \%)$ & & & Not \\
NEED FOR RESCUE & $15(93.8 \%)$ & $15(93.8 \%)$ & Chi Square & 0.758 & Significant \\
ANALGESICS & $1(6.3 \%)$ & $1(6.3 \%)$ & & & Not \\
NO/YES & $1(6.3 \%)$ & $1(6.3 \%)$ & & \multirow{2}{*}{0.887} & Significant \\
\hline PATIENT SATISFACTION & $2(12.5 \%)$ & $3(18.8 \%)$ & Chi Square & & \\
BAD/FAIR/GOOD & $13(81.3 \%)$ & $12(75 \%)$ & & & \\
\hline
\end{tabular}

There is no statistical significance between the two patch, eluting drug @ 20mcg/hr, each patch for 7 days) groups with respect to incidence of diarrhoea, need and patient satisfaction. for rescue analgesics (buprenorphine transdermal NeEd fOR Rescue Analgesics in Both THE Groups (IDEntically Same Cylinder GRAPHS)

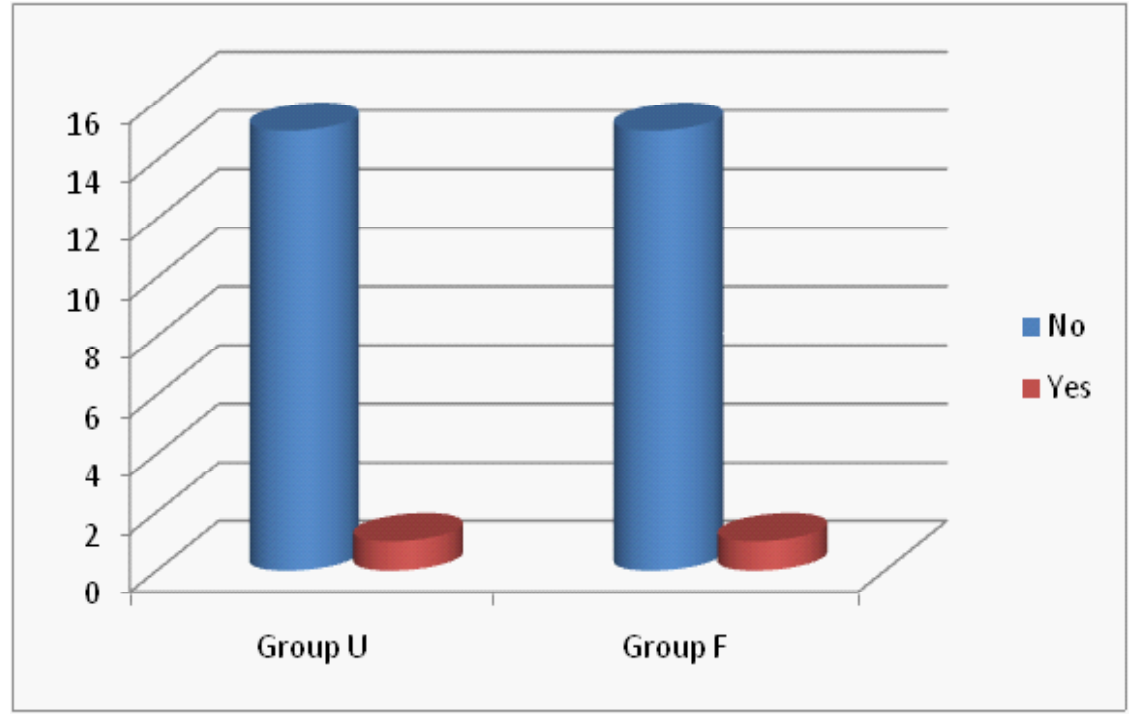


Comparison of Ultrasonogaphy Vs Fluoroscopy Guided Coeliac Plexus Block for Relief of Pain in Chronic Pancreatitis - An Observational Study

\section{DISCUSSION}

The rationale of combining a local anaesthetic with a long acting depo-steroid preparation is firstly to block the neuronal transmission generating pain and secondly to reduce the chronic inflammation associated with chronic pancreatitis. The combined effect along with lifestyle modification, pancreatic enzyme supplementation and pain modifying drugs significantly reduce patient morbidity and pain free days (improved patient satisfaction).

Our study is a pilot study involving only 32 patients with 16 patients each in Group U and Group F. This study hints at pros and cons of each method.

Most of the patients who are chronic alcoholic have suffered from pancreatitis whereas only a small percentage are chronic smokers. The difference in these data between the two groups are not statistically significant.

The study establishes that USG guided block can be done faster than Fluoroscopy guided technique. This is because fluoroscopy requires elaborate settings of the C-arm and needle advancement/withdrawal needs to be confirmed each time with a shot of the $\mathrm{C}$-arm.Whereas continuous monitoring of the needle advancement is possible in USG. This explains the fastness to needle placement in USG guided technique. On the other hand Fluroscopy provides a view of the needle with much more clarity than USG. Our study clearly upholds this fact, the p value being 0.000 (fastness of needle placement between the two groups)

The VAS score at the end of 3 months was lower in USG guided procedure than Fluoroscopy guided. Immediate post-procedure and at end of 2 weeks the VAS scores were identical in both groups. Most patients undergoing Fluoroscopy guided procedure reach onethird of their pre-op scores at end of 3weeks, whereas those undergoing USG guided block, reached one-third of their pre-op VAS scores at end of 12 weeks. USG enables accurate visualization of the abdominal aorta and the "hooded" appearance of the celiac plexus over it. So the needle placement is more accurate thereby deposition of the drug is more precise. The result is somewhat similar to the works of Santoshet $\mathrm{al}^{2}$.

As per works of Santosh et $\mathrm{al}^{2} 26$ out of 27 subjects undergoing endoscopic USG guided block had pain reiefimmediatey, 22 out of 27 had pain relief after 4weeks, 17 out of 27 after 8 weeks and 8 out of 7 after 12 weeks. In their study those undergoing fluoroscopic guided technique 28 out of 29 patients had pain relief immediately, 11 out of 29 had relief after 4weeks, 8 out of 29 after 8 weeks, 3 out of 29 after 12 weeks. [Ref 2]

Montero Matamala et $\mathrm{al}^{5}$ reports total pain relief in 7 out of 9 chronic pancreatitis patients undergoing CPB after 2 weeks and in 5 after 5 months. [Ref 5]

Ghai et al ${ }^{6}$ reports significant reduction in VAS scores at $1 \mathrm{hr}, 1$ week, 4weeks, 8 weeks and 12 weeks respectively in 15patients undergoing ultrasound guided CPB in 15 chronic pancreatitis patients. There is also significant decrease in rescue analgesics. [Ref 6]

The fall in Systolic BP is more at 15 mins in USG guided block while it is significantly lower at $30 \mathrm{mins}$ in fluoroscopy guided technique. A probable explanation is that the mean time of needle placement is around 13 mins in USG guided technique and 29 mins in Fluoroscopy guided procedure. Hence the difference. The same reason explains fall of diastolic BP at $15 \mathrm{mins}$ in USG guided procedure than the other.

In each Group only 1 out of 16 patients needed rescue analgesics within 3 months of coeliac plexus block. The rest 15 in each group did well without need for rescue analgesics. Yang et $\mathrm{al}^{4}$ in their study(coeliac plexus neurolysis), reports morphine usage of (155 \pm 56) $\mathrm{mg} /$ day which was reduced to $0 \mathrm{mg} /$ day at end of 1 week and $(42 \pm 44) \mathrm{mg} /$ day at end of 3months.

The patient satisfaction at the end of 3months is comparable in both the groups. It was categorised as good/fair/bad. 13 out of 16 patients in Group U and 12 out of 16 patients in Group F have reported the procedure as good. However patients are more comfortable with USG guided technique. Fluoroscopy involves prone positioning and more time which was uncomfortable to the patient. Moreover each time needle advancement/withdrawal needs confirmation with a shot of the $\mathrm{C}$-arm which is uncomfortable to the patient.

Diarrhoea was observed in 2 patients in Group U and 3 patients in Group F (out of 16 in each group). This was found to be statistically insignificant. Santoshet $\mathrm{al}^{2}$ also reports diarrhoea in 2 out $\mathrm{f} 27$ patients undergoing endoscopic ultrasound guided Coeliac plexus block. 
Comparison of Ultrasonogaphy Vs Fluoroscopy Guided Coeliac Plexus Block for Relief of Pain in Chronic Pancreatitis - An Observational Study

\section{CONCLUSION}

- The time of needle placement was faster in ultrasonography guided procedure.

- In the long term ultrasonography guided procedure yields greater reduced VAS scores.

- The fall in systolic BP in $15^{\text {th }}$ minute was more in ultrasound guided procedure and fall in systolic BP was more in fluoroscopy guided procedures respectively.

- Patient satisfaction, side-effects, reduction in rescue analgesics were comparable in both groups.

- Ultrasound is a safer, quicker, safer alternative to Fluoroscopy with comparable or even better results.

- Strict lifestyle changes, pain perception modification and significantly cut down morbidity in chronic pancreatitis.

\section{REFERENCES}

[1] Jain P, Dutta A, Sood J.Coeliac plexus blockade and neurolysis: An overview. Indian J Anaesth 2006;50:169.

[2] Santosh, D. et al.Clinical trial: a randomized trial comparing fluoroscopy guided percutaneous technique vs. endoscopic ultrasound guided technique of coeliac plexus block for treatment of pain in chronic pancreatitis. Aliment. Pharmacol. Ther. 29, 979-984 (2009).

[3] Dhamija E, Khandelwal I, Bhatnagar S, Thulkar $S$. A systematic approach to give bedside ultrasound-guided celiac plexusblock. Indian J Pain 2017;31:80

[4] Feng-Rui Yang et al. Assessmnt of Consequtive Neuolytic Coeliac Plexus Block (NCPB) Technique outcomes in management of Refractory Visceral Cancer pain.

[5] Montero Matamala A, Vidal Lopez F, aguilar Sanchez JL, Donosobach L. Percutaneous anterior approach to the coeliac plexus using ultrasoung. Br J Anaesth 1989:62:637-40

[6] Ghai A, Kumar H, Karwasra RK, Kad N, Rohilla S, ParsadS.Ultrasoundguided celiacplexusneurolysis by anterior approach for pain management in upper abdominal malignancy: Our experience. Anaesth Pain Intensive Care 2015;19:274-81.

[7] Gachago C, Draganov PV. Pain management in chronic pancreatitis. World J Gastroenterol2008; 14(20): 3137-3148

[8] Michaels AJ, Draganov PV. Endoscopic ultrasonography guided celiac plexus neurolysis and celiac plexus block in the management of pain due to pancreatic cancer and chronic pancreatitis. World J Gastroenterol2007; 13: 3575-80.

[9] Sehgal and Ghaleb: Neurolytic celiac plexus block for pancreatic cancer painIndian Journal of Pain / September-December 2013 | Vol 27 | Issue 3

[10] PietroFusaroli, Giancarlo Caletti: Is there a role for celiac plexus block for chronic pancreatitis?Endoscopy International Open 2015; 03: E60-E62

[11] Bhatnagar S, Gupta D, Mishra S, Thulkar S, Chauhan H. Bedside ultrasound-guided celiac plexus neurolysis with bilateral paramedian needle entry technique can be an effective pain control technique inadvanced upper abdominal cancer pain. J Palliat Med 2008;11:1195-9.

[12] Das KM, Chapman AH. Sonographically guided coeliac plexus block. ClinRadiol 1992;45:401-3.

Citation: Dr. Sourav Mallik, Dr. Dipasri Bhattacharya, Dr. Sankar Roy. Comparison of Ultrasonogaphy Vs Fluoroscopy Guided Coeliac Plexus Block for Relief of Pain in Chronic Pancreatitis - An Observational Study. Archives of Anesthesiology. 2019; 2(1): 15-24

Copyright: (C) 2019 Dr. Sourav Mallik, Dr. Dipasri Bhattacharya, Dr. Sankar Roy. This is an open access article distributed under the Creative Commons Attribution License, which permits unrestricted use, distribution, and reproduction in any medium, provided the original work is properly cited. 